\title{
SURGICAL MANAGEMENT OF TIBIAL PLATEAU FRACTURES WITH LOCKING COMPRESSION PLATE
}

\author{
Bipan Shrestha, ${ }^{1}$ Prakriti Raj Kandel, ${ }^{1}$ Kishor Man Shrestha, ${ }^{1}$ Shreshal Shrestha, ${ }^{1}$ Rakesh Yadav ${ }^{2}$
}

\begin{abstract}
INTRODUCTION

Tibial plateau fracture is a common fracture that accounts for $1-2 \%$ of all fracture. Various treatment options including proximal tibial plating with locking compression plates are available for the treatment of tibial plateau fracture. This study was done to determine the clinical profile and functional outcome of tibial plateau fracture following locking compression plating.
\end{abstract}

\section{MATERIAL AND METHODS}

This prospective and observational study was carried out in Orthopedics Department of Universal College of Medical Sciences-Teaching Hospital (UCMS-TH) from December 2018 to July 2020. After ethical clearance (UCMS/IRC/224/18) from Institutional Review Board (IRB) of UCMS-TH and informed written consent, all patients with tibial plateau fracture (Schatzker II-VI) who fulfilled the inclusion criteria were enrolled in the study and treated with locking compression plate. Post-operatively patients were regularly followed at 6 weeks, 3 months and 6 months for clinical, radiological and functional assessment. Descriptive statistics like frequency, percentage, mean and standard deviation were used to analyze the data.

\section{RESULTS}

In our study of 30 cases, the mean age was $37.77 \pm 15.65$ years. Most of the cases were Schatzker type VI (13 patients) and type II ( 9 patients). The average duration for fractures union was $23.4 \pm 2.1$ weeks. Superficial wound infection was the common complication seen in five cases. At six months, the mean knee society score (KSS) was $78 \pm 7.22$ and majority of patients (19 patients) had good results.

\section{CONCLUSION}

Locking compression plate has an excellent functional and radiological outcome. It is an effective implant that can be adopted for the treatment of tibial plateau fractures in adults.

\section{KEYWORDS}

Functional outcome, Locking compression plate, Tibial plateau fracture.

1. Department of Orthopaedics and Trauma Surgery, Universal College of Medical Sciences, Bhairahawa, Nepal

2. Resident, Department of Orthopaedics and Trauma Surgery, Universal College Medical Sciences, Bhairahawa, Nepal

DOI: http//doi.org/10.3126/jucms.v9i01.37953

\author{
For Correspondence \\ Dr. Bipan Shrestha \\ Department of Orthopaedics \& Trauma Surgery \\ Universal College of Medical Sciences \& Teaching Hospital, \\ Bhairahawa, Nepal \\ E-mail:bipansht@hotmail.com
}




\section{INTRODUCTION}

Tibial plateau fracture accounts for $1-2 \%$ of all fractures and contributes $8 \%$ of fractures in the elderly.' Tibial plateau fractures are the common proximal tibial fractures generally caused by high energy trauma e.g. road traffic accident (RTA). Tibial plateau fracture ranges from simple lateral condyle fracture to severely comminuted metaphyseal fractures and are often associated with severe soft tissue compromise. Though difficult, the treatment of these fractures aims to restore normal knee joint function by anatomical restoration of joint surfaces and maintaining the reduction by stable implants.

Various treatment options including proximal tibial plating with locking compression plates are available for the treatment of tibial plateau fracture. In the past, fracture treated with older non anatomical plates ended with fracture collapse, joint incongruity and malunion. But, now precontoured anatomical locking compression plate (LCP) is considered the implant of choice, which is designed to prevent all these complication. ${ }^{4}$ Therefore, with the advent of this LCP, even complex tibial plateau fractures which were once considered difficult to treat, are now having successful outcomes.

Thus, with this background we have conducted this study to determine the clinical, radiological and functional outcome of tibial plateau fracture managed with proximal tibial locking compression plates.

\section{MATERIAL AND METHODS}

\section{Study design, place and duration of study}

This prospective hospital-based, longitudinal and observational study was carried out in Department of Orthopaedics of Universal College of Medical Sciences \& Teaching Hospital, (UCMS-TH), Bhairahawa, Nepal from December 2018 to July 2020.

\section{Ethical approval and patient consent}

After ethical clearance (UCMS/IRC/224/18) from Institutional Review Board (IRB) of UCMS-TH, all patients with tibial plateau fracture (Schatzker type II to VI), who fulfilled the inclusion criteria were enrolled in the study. Patients were informed about the purpose of the study and written consent was taken. Cases were admitted either via outpatient department (OPD) or Emergency department of UCMS-TH. Data collection was done by the researcher.

\section{Sample size and sampling technique}

The targeted sample size after using the sample size formula was 30 . So, approximately convenient sample of 30 patients were selected by using purposive sampling technique. $\mathrm{n}=\mathrm{z}^{2} \mathrm{pq} / \mathrm{d}^{2}$

[n=required sample size; $\mathrm{p}=$ prevalence of disease $(2 \%) ; 1$ $\mathrm{q}=100-\mathrm{p} ; \mathrm{z}=1.96$ taken at $95 \%$ confidence interval; $\mathrm{d}=$ allowable error taken as 5\%; $\mathrm{P}=2 \%, \mathrm{q}=98 \%$ ]

\section{Inclusion criteria}

1. Schatzker type II to VI tibial plateau fracture

2. Age $\geq 18$ years

\section{Exclusion criteria}

1. Polytrauma patients and head injury patients

2. Open fractures

3. Neuromuscular problems

4. Pathological fractures

5. Previous fracture of same limb

\section{Patient management}

All stable patients with isolated tibial plateau fracture were admitted either via emergency or OPD. Detailed history and systemic examination was done to rule out any other comorbidity. Before admission to ward, all preoperative investigation, along with CT scan if needed, was sent. Depending on the radiological findings, fracture was classified according to Schatzker classification. Preoperatively patients were managed by analgesics, antiswelling agents, limb elevation and knee immobilizer. Skeletal traction was applied to patients with coexisting comorbidities who were likely to require a longer duration for surgery clearance and optimization for surgery.

\section{Surgical technique}

In the operation theatre, prophylactically all patients were given cefuroxime (1.5 gram) intravenous injection half an hour before surgery. After spinal anaesthesia, patient was placed in a supine position with thigh tourniquet on injured limb and bolster under knee to allow knee flexion. Various approaches were used for tibial plateau fracture depending on the location and type of fracture fragment (Schatzker classification). For type II and III fracture, lateral plating was done using antero-lateral approach. For Type IV fracture, medial plating was done. For type V and VI fracture, double plating from medial and lateral approach was done. Those with isolated or combined posterior tibial condyle fracture, isolated posterior plating or combined posterior plating was done via posterior, postero-medial or postero-lateral approach depending on fracture anatomy. The plate used was anatomically precontoured medial, lateral and posterior LCP. For complex fractures additional $3.5 \mathrm{~mm}$ distal radius volar LCP was used. ${ }^{7.8}$ (Figure 1,2) 


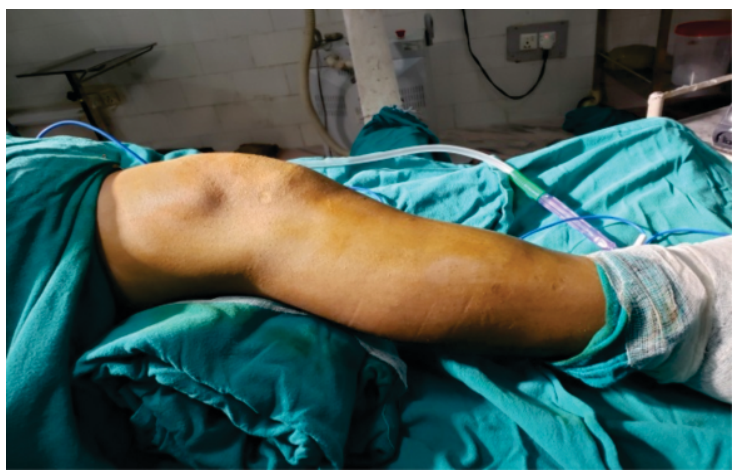

Figure 1. Painting and draping

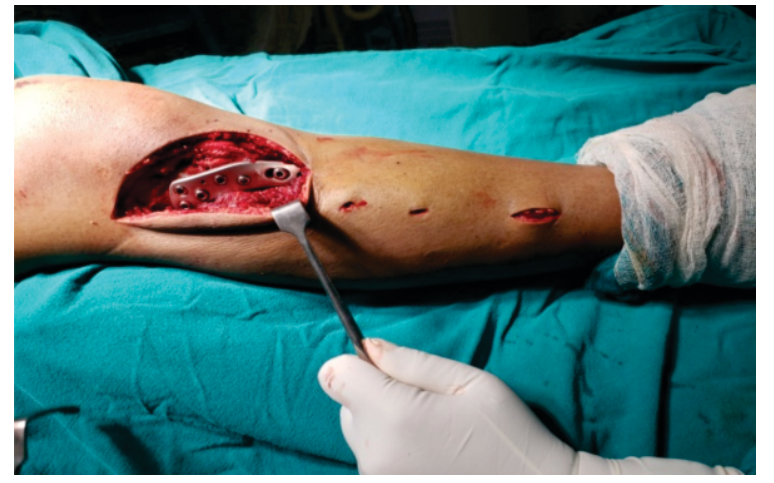

Figure 2. Fixation by LCP

Post-operatively, X-ray of knee was taken on the day of surgery. Analgesics and antibiotics were given for days to weeks depending upon the patient's pain tolerance and wounds status respectively. Postoperative immobilization was done by knee immobilizer with intermittent regular active and passive quadriceps and knee range of motion physiotherapy. Non-weight-bearing axillary crutch walking was started as soon as possible depending on patient's pain tolerance. Wound dressing was done on the $3^{\text {rd }}, 6^{\text {th }}$ and $10^{\text {th }}$ day and suture removal on $14^{\text {th }}$ postoperative day. Generally, patients were discharged between 7 to 14 days depending upon the condition of the wound.

Regular follow ups were done at 6 weeks, 3 months, and 6 months. In every follow-up, patient's clinical and radiographic findings, range of motion and patient's daily functional activity were assessed and recorded. Finally at 6 months, functional assessment of knee was assessed by using the Knee Society Score.' Complications such as wound infection were treated by regular dressing, debridement and antibiotics. Radiological evaluation was made based on the signs of union of fracture, fracture collapse, malunion and implant loosening or failure. Union was considered when at least 3 cortices were united in X-ray. At six-weeks partial weight-bearing walking and at three months, full weight-bearing walking was allowed.

\section{Statistical analysis}

All the data was collected in a proforma that included patients demographic profile, general history, clinical and radiological findings, its management and regular follow up. Data were entered and analyzed by SPSS Vs.20. Descriptive statistics like frequency, percentage; mean and standard deviation were used to analyze the data.

\section{RESULTS}

In this study, the mean age group was $37.77 \pm 15.65$ years ranging from 18 years to 65 years and male patients outnumbered female patients (26 males and 4 females) with male to female ratio of 13:2. Out of 30 cases, 21 cases (70\%) were of the right side and 9 cases $(30 \%)$ were of the left side. Majority of fractures were due to road traffic accident $(93.3 \%)$ followed by fall injury $(6.7 \%)$. (Table 1$)$

Majority of cases were Schatzker Type VI (13 patients;43.3\%) and Type II ( 9 patients; $30 \%$ ). Most of the cases were operated within 5-10 days (16 cases/53.3\%) and within 5 days of trauma (11 cases/36.7\%) with a mean of $6.33 \pm 2.74$ days between trauma and surgery. (Table 1,2)

Table 1. Demographic and clinical characteristics of the study population

\begin{tabular}{|c|c|c|c|}
\hline Variables & & $\begin{array}{l}\text { Frequency } \\
(n=30)\end{array}$ & Percentage $(\%)$ \\
\hline \multirow[t]{4}{*}{ Age (years) } & $18-38$ & 18 & 60 \\
\hline & $39-58$ & 7 & 23.3 \\
\hline & $\geq 59$ & 5 & 16.7 \\
\hline & \multicolumn{3}{|c|}{ Mean age $=37.77 \pm 15.65$ years } \\
\hline \multirow[t]{2}{*}{ Sex } & Male & 26 & 86.7 \\
\hline & Female & 4 & 13.3 \\
\hline \multirow[t]{2}{*}{ Side affected } & Left & 9 & 30 \\
\hline & Right & 21 & 70 \\
\hline \multirow[t]{2}{*}{ Mode of injury } & RTA & 28 & 93.3 \\
\hline & Fall injury & 2 & 6.7 \\
\hline \multirow[t]{5}{*}{ Schatzker classification } & Type II & 9 & 30 \\
\hline & Type III & 1 & 3.3 \\
\hline & Type IV & 4 & 13.3 \\
\hline & Type V & 3 & 10 \\
\hline & Type VI & 13 & 43.3 \\
\hline \multirow[t]{3}{*}{ Duration between trauma and surgery (days) } & $<5$ days & 11 & 36.7 \\
\hline & 5-10 days & 16 & 53.3 \\
\hline & $>10$ days & 3 & 10 \\
\hline
\end{tabular}

The mean duration of fracture union was a $23.4 \pm 2.11$ week ranging from 21-26 weeks. Only 6 patients (20\%) had minor complication like superficial wound infection and hardware related pain that was seen in 5 patients $(16.7 \%)$ and 1 patient $(3.3 \%)$ respectively. (Table 2,3$)$

At 6 months, majority of cases (19 patients) had good results where 10 patients were from Schatzker type VI. The mean 
knee society score was $78 \pm 7.22$ where Schatzker type III, Type II and VI had mean of $85,83.33 \pm 4.33$ and $83.75 \pm 2.5$ respectively. Majority of patients (18 patients) had knee flexion of 90-120 degree where 12 cases were of Schatzker type VI and the average knee flexion of all types was 114.50 \pm 13.79 . (Table 2,3)

Table 2. Complications and outcome of tibial plateau fracture treated with LCP

\begin{tabular}{lccc}
\hline Variables & & $\begin{array}{c}\text { Frequency } \\
(\mathrm{n}=30)\end{array}$ & $\begin{array}{c}\text { Percentage } \\
(\%)\end{array}$ \\
\hline Complications & Superficial Infection & 5 & 16.7 \\
Fracture union (weeks) & Hardware related pain & 1 & 3.3 \\
& 20 & 2 & 6.6 \\
& 21 & 2 & 6.6 \\
& 22 & 5 & 16.6 \\
& 23 & 6 & 20 \\
Outcome (knee society score at 6 & 24 & 10 & 33.3 \\
months) & 25 & 3 & 10 \\
& 26 & 2 & 6.6 \\
& Poor (<60) & 2 & 6.7 \\
Knee flexion at 6 months (degree) & Fair (60-69) & 0 & 0 \\
& Good (70-84) & 19 & 63.3 \\
& Excellent (85-100) & 9 & 30 \\
& $<90$ & 1 & 3.3 \\
& $90-120$ & 18 & 60 \\
& $>120$ & 11 & 36.7 \\
\hline
\end{tabular}

Table 3. Analysis of complication and outcome with respect to Schatzker type

\begin{tabular}{|c|c|c|c|c|c|c|c|}
\hline \multirow[t]{2}{*}{ Variables } & & \multicolumn{6}{|c|}{ Schatzker classification } \\
\hline & & Type II & Type III T & Type IV & Type $V$ & Type VI & Total \\
\hline \multirow{3}{*}{$\begin{array}{l}\text { Interval between trauma and surgery } \\
\text { (days) }\end{array}$} & $<5$ days & 9 & 0 & 2 & 0 & 0 & 11 \\
\hline & $5-10$ days & 0 & 1 & 2 & 3 & 10 & 16 \\
\hline & $>10$ days & 0 & 0 & 0 & 0 & 3 & 3 \\
\hline Average duration (days) & & $3.33 \pm .86$ & $6 \pm 0$ & $5.25 \pm 2.21$ & $6.67 \pm 1.52$ & $8.69 \pm 1.70$ & $6.33 \pm 2.74$ \\
\hline \multirow[t]{2}{*}{ Complication } & Infection & 1 & 0 & 0 & 1 & 3 & 5 \\
\hline & Pain & 0 & 0 & 0 & 0 & 1 & 1 \\
\hline Average fracture union (weeks) & & $20.66 \pm 1.11$ & $1123 \pm 0$ & $23.25 \pm .95$ & $24.66 \pm .57$ & $25.07 \pm .75$ & $23.4 \pm 2.11$ \\
\hline \multirow[t]{3}{*}{ Knee flexion (degree) } & $<90$ & 0 & 0 & 0 & 0 & 1 & 1 \\
\hline & $90-120$ & 0 & 0 & 3 & 3 & 12 & 18 \\
\hline & $>120$ & 9 & 1 & 1 & 0 & 0 & 11 \\
\hline Average knee flexion (degree) & & $128.33 \pm 2.5$ & $.5125 \pm 0$ & $121.25 \pm 2.5$ & $5110 \pm 10$ & $103.08 \pm 11.0$ & $09114.50 \pm 13.79$ \\
\hline \multirow{2}{*}{ Average KSS at 6 months (points) } & & $83.33 \pm 4.33$ & $3385 \pm 0$ & $83.75 \pm 2.5$ & $71.67 \pm 2.88$ & $873.46 \pm 7.74$ & $78 \pm 7.22$ \\
\hline & Poor & 0 & 0 & 0 & 0 & 2 & 2 \\
\hline Functional outcome at 6 months by & Good & 5 & 0 & 1 & 3 & 10 & 19 \\
\hline KSS & Excellent & 4 & 1 & 3 & 0 & 1 & 9 \\
\hline
\end{tabular}

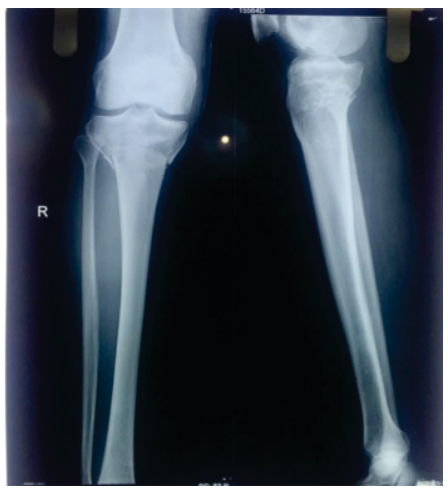

Figure 3. Preoperative X ray

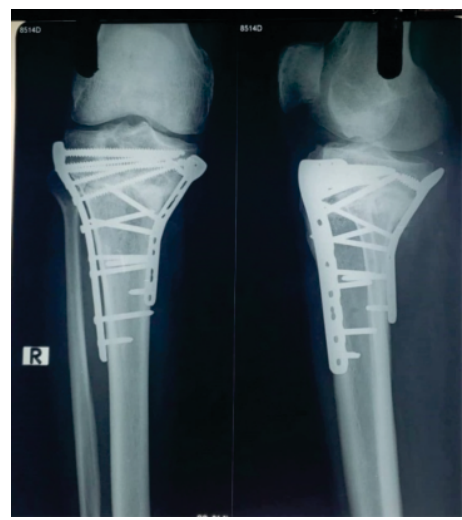

Figure 4. Six month follow up

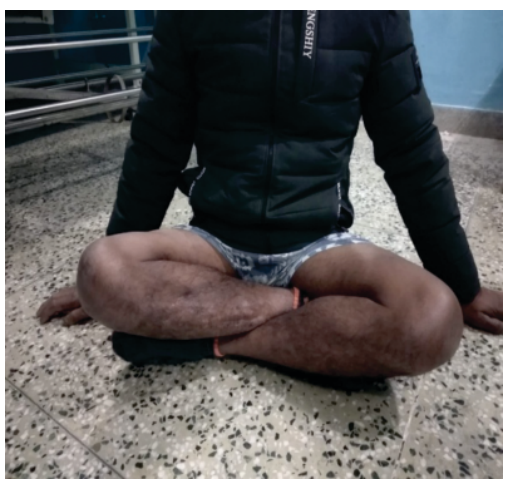

Figure 5. Cross leg sitting

\section{DISCUSSION}

Various surgical treatment options including locking compression plates are in use to treat tibial plateau fracture. ${ }^{3,4}$ Proximal tibial LCP system is associated with better functional outcome, decrease in fracture union time and overall complications. ${ }^{10}$

In our study, the mean age group was $37.77 \pm 15.65$ years with majority of patient's (18 patients) age between 18 to 38 years. Similar results was seen in Mahendra et $\mathrm{al}^{11}$ study and Henley et $\mathrm{al}^{12}$ study where the mean age group was 39.03 years and 33 years which is similar to our study. There were 26 males $(86.7 \%)$ and 4 females $(13.3 \%)$ in our study. Similar results was seen in Somashekhara et $\mathrm{al}^{13}$ study, where out of 30 patients, $25(83.33 \%)$ were male and only $5(16.66 \%)$ were female. In this study, out of 30 patients 21 cases $(70 \%)$ were of the right side and 9 cases (30\%) were of the left side which is similar to Imran et $\mathrm{al}^{14}$ study where $63.3 \%$ fracture were of right side and $36.7 \%$ were of left side. In this study, the major cause of fracture was road traffic accident $(93 \%)$ followed by fall injury (7\%) which is similar to study done by Prabkhar et $\mathrm{al}^{15}$ where all 21 fractures $(100 \%)$ were due to road traffic accidents.

In this study, majority of cases were of Schatzker Type VI (13 
cases/43.3\%) and Type II ( 9 cases/30\%) which is similar to Venkatesh et $\mathrm{al}^{16}$ study, where majority of cases were Schatzker Type VI; and Albuquerque et al where type II (35.14\%) and type VI (20.03\%) accounted for majority of cases. In Nokolaos et al ${ }^{17}$ study of 125 patients, Schatzker type II (42 cases/33.6\%) was the common fracture type which is also similar to our study. In this study, most of the cases were operated between 5-10 days of trauma (16 cases/53.3\%) and within 5 days ( 11 cases $/ 36.7 \%$ ) and with a mean of $6.33 \pm 2.74$ days between trauma and surgery which is similar to Peter A. Cole et $\mathrm{al}^{18}$ study where the mean time between trauma and surgery was 7.1 days.

The mean duration of fracture union was $23.4 \pm 2.11$ weeks ranging from 21-26 weeks which is similar to Girish et al ${ }^{19}$ and Kancherla NR et al ${ }^{20}$ where the mean duration of fracture union was 22 weeks (15-24 weeks) and 19 weeks (16-24 weeks) respectively. But in Nokolaos et $\mathrm{al}^{17}$ study, the average time to union was 13 weeks ( $8-36$ weeks) which is not similar to our study which could be due to larger sample size, longer duration of these study and difference in fracture union criteria.

Only 6 patients (20\%) had minor complication like superficial wound infection and hardware related pain that was seen in 5 patients $(16.7 \%)$ and one patient $(3.3 \%)$ respectively which is similar to Nokolaos et $\mathrm{al}^{17}$ study where $15.2 \%$ suffered superficial wound infection. Similar results were also seen in Sven et $\mathrm{al}^{21}$ study where superficial wound infection and hardware related pain was seen in $15.8 \%$ and $18 \%$ respectively. All cases were successfully treated with local wound care and antibiotics.

At 6 months, majority of cases (19 patients) had good results where 10 patients were from Schatzker type VI. The mean knee society score was $78 \pm 7.22$. Similar result was seen in study done by Mohammad Ali et $\mathrm{al}^{10}$, where the mean knee society score was 80.2. But in Vassilios et $\mathrm{al}^{2}$ and Yukai Wang et $\mathrm{al}^{\mathrm{P}^{3}}$ study the mean knee society score was 89 and 93 respectively which is better than our study which could be due to difference in sample size and duration of these studies.

\section{CONCLUSION}

Locking compression plate is a time demanded implant of choice for treating Schatzker type II-VI tibial plateau fracture as it is associated with excellent functional and radiological outcome; early fracture union and minimal manageable complication.

\section{LIMITATIONS AND RECOMIMNDATIONS}

The major limitation of this prospective study is the small sample size and short duration of study. A further prospective study with a larger number of patients and for longer duration of time is recommended for a more appropriate result.

\section{CONFLICT OF INTEREST}

The authors declare no conflict of interest in publication of this paper.

\section{REFERENCES}

1. Albuquerque RP, Hara R, Prado J, Schiavo L, Giordano V, Amaral NPd. Epidemiological study on tibial plateau fractures at a level I trauma center. Acta Ortopedica Brasileira. 2013;21(2):109-15.

2. Lachiewicz PF, Funcik T. Factors influencing the results of open reduction and internal fixation of tibial plateau fractures. Clin Orthop Relat Res. 1990 Oct;(259):210-5.

3. Tscherne H, Lobenhoffer P. Tibial plateau fractures. Management and expected results. Clin Orthop Relat Res. 1993;(292):87-100.

4. Farouk O, Krettek C, Miclau T, Schandelmaier P, Guy P, Tscherne H. Minimally invasive plate osteosynthesis: does percutaneous plating disrupt femoral blood supply less than the traditional technique? Journal of Orthopaedic Trauma. 1999;13(6):401-6.

5. Bartoníček J. Early history of operative treatment of fractures. Archives of Orthopaedic and Trauma Surgery. 2010;130(11): 1385-96.

6. Schatzker J, Mcbroom R, Bruce D. The tibial plateau fracture: the Toronto experience 19681975. Clin Orthop Relat Res. 1979;(138):94-104.

7. Wenger D, Petersson K, Rogmark C. Patient-related outcomes after proximal tibial fractures. International Orthopaedics. 2018;42(12):2925-31.

8. Kandemir U, Maclean J. Surgical approaches for tibial plateau fractures. The Journal of Knee Surgery. 2014;27(01):021-30.

9. Insall JN, Dorr LD, Scott RD, Scott WN. Rationale of the Knee Society clinical rating system. Clin Orthop Relat Res. 1989;(248):13-4.

10. Tahririan MA, Mousavitadi SH, Derakhshan M. Comparison of functional outcomes of tibial plateau fractures treated with nonlocking and locking plate fixations: A nonrandomized clinical trial. ISRN Orthop. 2014 Mar;2014:324573.

11. Aseri MK, Singh V, Sharma PK. Functional outcome of proximal tibial fracture treated surgically using locking compression plate. Int J Res Orthop. 2018;4:400-5.

12. Henley M, Chapman J, Agel J, Harvey E, Whorton A, Swiontkowski M. Treatment of type II, IIIA, and IIIB open fractures of the tibial shaft: a prospective comparison of 
unreamed interlocking intramedullary nails and half-pin external fixators. Journal of Orthopaedic Trauma. 1998;12(1):17.

13. Somashekara S. Functional outcome assessment of columnar fixation in proximal tibia fractures: A prospective study. International Journal of Orthopaedics. 2020;6(1):491-6.

14. Imran $Y$, Vishvanathan T. Does right leg require extra protection? Five-year review of type 3 open fractures of the tibia. Singapore Medical Journal. 2004;45:280-2.

15. Manoj Kumar R. A study on clinical, functional and radiological outcome of high velocity tibial plateau fractures managed by dual plating: Kilpauk Medical College, Chennai; 2016.Thesis (Master's)

16. Kumar NV, Arvind Kumar S, Udayamoorthy S, Sanjeev S. Functional outcome of tibial condyle fractures treated by minimally invasive plate osteosynthesis. International Journal of Orthopaedics. 2017;3(1):792-6.

17. Manidakis N, Dosani A, Dimitriou R, Stengel D, Matthews S, Giannoudis P. Tibial plateau fractures: functional outcome and incidence of osteoarthritis in 125 cases. International Orthopaedics. 2010;34(4):565-70.

18. Cole PA, Zlowodzki M, Kregor PJ. Treatment of proximal tibia fractures using the less invasive stabilization system: surgical experience and early clinical results in 77 fractures. Journal of Orthopaedic Trauma. 2004;18(8):528-35.

19. Vasanad GH, Antin S, Akkimaradi R, Policepatil P, Naikawadi G. Surgical management of tibial plateau fractures. A clinical study. Journal of Clinical and Diagnostic Research: JCDR. 2013;7(12):3128-3130.

20. Kancherla NR, Hussain KSA, Sreenath M, Chilakamarri VK. Outcome of treatment of proximal tibial plateau fractures by minimally invasive percutaneous plating osteosynthesis technique. Int J Res Orthop. 2016;2(3):132-7.

21. Märdian S, Landmann F, Wichlas F, Haas NP, Schaser K-D, Schwabe P. Angular-stable locking plate fxation of tibial plateau fractures-clinical and radiological midterm results in 101 patients. Indian Journal of Orthopaedics. 2015;49:620-9.

22. Nikolaou VS, Tan HB, Haidukewych G, Kanakaris N, Giannoudis PV. Proximal tibial fractures: early experience using polyaxial locking-plate technology. International Orthopaedics. 2011;35(8):1215-21.

23. Wang Y, Luo C, Zhu Y, Zhai Q, Zhan Y, Qiu W, et al. Updated three-column concept in surgical treatment for tibial plateau fracturesa prospective cohort study of 287 patients. Injury. 2016;47(7):1488-96. 